\title{
Caracterização anatômica, histoquímica e de classes de metabólitos secundários de folhas de Guzmania lingulata (L.) Mez.
}

\author{
BELOTTO, E.M. ${ }^{1 *}$; SOUZA-LEAL, T. ${ }^{1}$; PARALUPPI, A.L. ${ }^{1}$; FURTADO, A.L.F.F. ${ }^{1}$; GASPI, F.O.G. ${ }^{1}$; PEDROSO- \\ DE-MORARES, C. ${ }^{1}$ \\ ${ }^{1}$ Centro Universitário Hermínio Ometto - Uniararas. Rua Maximiliano Baruto, 500, Jd. Universitário. 13607-330. \\ Araras, SP. emiliemb@gmail.com
}

\begin{abstract}
RESUMO: Na medicina natural pouco se sabe sobre a importância curativa da maior parte das espécies pertencentes à Bromeliaceae. Tal fato evidencia a necessidade da realização de investigações para a comprovação de possíveis potenciais fitoterápicos em espécies dessa família. Guzmania lingulata é caracterizada como sendo uma das espécies de bromélia mais comercializada e conhecida popularmente, a qual é amplamente propagada no Brasil. O presente trabalho objetivou a caracterização anatômica e a identificação de classes de metabólitos secundários presentes em G. lingulata, por meio de análises anatômicas, histoquímicas e químicas. As folhas foram fixadas em FAA 50 e transferidas para etanol $50 \%$. Para o estudo anatômico, secções transversais da porção mediana das lâminas foliares foram obtidas à mão livre e submetidas ao processo de dupla coloração com safranina e azul de astra, sendo, logo após, montadas em gelatina glicerinada. Para a triagem das classes de metabólitos secundários foram coletadas 10 folhas frescas que passaram pelo processo de maceração em solução hidroalcoólica $70 \%$ por sete dias, à temperatura ambiente. $O$ filtrado resultante da filtração a vácuo foi evaporado sob vácuo a temperatura de $50^{\circ} \mathrm{C}$ até a remoção total do etanol, sendo obtido desta forma o extrato bruto hidroalcoólico a frio (EBHF). Os resultados das secções histológicas permitiram a caracterização anatômico-foliar baseada na qualidade das secções manuais obtidas. Os testes em relação às classes de metabólitos secundários revelaram a presença de antocianinas e taninos e ausência de flavonóides e saponinas. Esses resultados estimulam a realização de estudos mais aprofundados para identificar e quantificar os compostos dessas e de outras classes de metabólitos.
\end{abstract}

Palavras-chave: Guzmania lingulata, antocianinas, taninos, anatomia foliar, Bromeliaceae.

ABSTRACT: Anatomical, histochemical and class characterization of secondary
metabolites in leaves ofGuzmania lingulata (L.) Mez. In natural medicine, little is known
about the healing importance of most of the species belonging to the family Bromeliaceae. Such
a fact points tothe need to perform investigations toprovethe possible phytotherapic potentials
in species of the family. Guzmania lingulata is characterized as one of the most popular well-
known and commercialized species of bromeliads, being widely spread in Brazil. This
work aimed at the anatomic characterization and identification of classes of the secondary
metabolites present in G. lingulata, by anatomic, histochemical and chemical analysis of
the leaves. The leaves were fixed in FAA 50 and, afterwards, transferred to $50 \%$ ethanol.
For the anatomic study, transverse sections of the middleproportion of the leafblades were
obtained by hand and exposed to the process of double coloration with safranin and astra
blue, being, right after that, mounted on glycerin jelly. For the sorting of the classes of
secondary metabolites, 10 fresh leaves were collected and then put through the maceration
process in $70 \%$ hydroalcoholic solution for 7 days, at room temperature. The resulting filtered
solution from the vacuum filtration was evaporated under vacuum at $40^{\circ} \mathrm{C}$ until the complete
removal of the ethanol, obtaining, this way, the cold crude hydroalcoholic extract (EBHF). The
results ofhistological sectionsallowed the anatomicalcharacterizationbased onthe quality ofthe
manual sectionsobtained. The testsin relationto the classes of secondary metabolitesrevealed

Recebido para publicação em 12/12/2011

Aceito para publicação em 20/02/2013

11_089

Rev. Bras. PI. Med., Campinas, v.16, n.1, p.127-134, 2014. 
the presence ofanthocyanins andtannins andabsence of flavonoids and saponins. These resultsencouragethe completionoffurther studiesto identify and quantifythe compoundsof these and otherclassesof metabolites.

Keywords: Guzmania lingulata, anthocyanins, tannins, leaf anatomy, Bromeliaceae

\section{INTRODUÇÃO}

Bromeliaceae Juss. possui 3010 espécies distribuídas em 56 gêneros (Luther, 2004). Encontrase tradicionalmente dividida em três subfamílias: Pitcairnioideae, Tillandsioideae e Bromelioideae. Esta família se destaca como uma das principais integrantes da flora e da fisionomia dos ecossistemas brasileiros, abrigando aproximadamente $36 \%$ das espécies catalogadas (Martinelli, 1994).

Guzmania Ruiz \& Pavon é um gênero botânico pertencente à subfamília Tillandsioideae. São plantas nativas do sudoeste da América do Sul, sendo conhecidas aproximadamente 140 espécies pertencentes a este gênero. A espécie mais conhecida popularmente é Guzmania lingulata (L.) Mez, chamada de "estrela escarlate", uma das plantas mais propagadas e comercializadas da família. Tal espécie apresenta folhas largas e macias, com textura coriácea e inflorescência formada por brácteas vermelhas e flores tubulares presentes em um longo escapo floral (Reitz, 1983).

Segundo Bennett (2000) a família Bromeliaceae apresenta uma longa história etnobotânica associada aos povos americanos nativos, sendo utilizada como fonte de fibras, alimentos, forragens e com propriedades medicinais, além de usos ornamentais e místicos. Segundo Benzing (2000) as antigas aplicações e percepções indígenas, nem sempre são coincidentes com seu uso moderno. Na medicina natural, a importância econômica das bromélias é destacada por algumas espécies que apresentam compostos ativos que melhoram os processos digestivos, urinários, respiratórios e agem como depurativos como, por exemplo, Ananas comosus (L.) Merr., Ananas sativus Schult \& Schult e Ananas muricata Schult (Corrêa, 1984; Cruz 1995; Duke et al., 2002; Rodrigues \& Carvalho, 2007). O decocto das raízes de macambira (Bromelia laciniosa Mart.) é usado popularmente contra hepatite e os frutos da Bromelia plumieri (E.Morren) L.B.Sm. Rank, conhecida frequentemente no Brasil como caroá ou como piñuela nos demais países latino-americanos, são consumidos como vermífugos (Agra et al., 2007).

No Piauí, o chá de croatá ou coroatá (Bromelia karatas L.) é usado contra coqueluche e gripe (Franco \& Barros, 2006). A espécie Nidularium procerum Lindm. apresenta importante potencial terapêutico, com destaque particular à atividade antialérgica, uma vez que apresenta potente atividade antieosinófila (Vieira-de-Abreu et al., 2005).

Na subfamília Tillandsioideae, a espécie mais estudada é a Tillandsia usneoides L. Esta espécie é conhecida popularmente no Caribe, México e Estados Unidos como Spanish moss (musgo espanhol), enquanto no Brasil é reconhecida como barba-de-velho ou barba-de-pau. No sul dos Estados Unidos, o chá feito desta espécie é utilizado para amenizar os sintomas do diabetes mellitus (Whiterup et al., 1995).

A espécie Tillandsia recurvata $\mathrm{L}$. é utilizada popularmente contra reumatismo, úlcera e hemorróida (Rios \& Khan, 1998; Agra et al., 2007). No Uruguai, as partes aéreas de Tillandsia aeranthos (Loisel.) L. B. Sm. são empregadas como antiespasmódico e para infecções oculares. Estudos mostraram que os extratos brutos desta espécie apresentaram atividade antimicrobiana (Alonso Paz et al., 1995)

Com relação ao uso etnobotânico e medicinal de espécies da subfamília Pitcairnioideae, não foram encontrados relatos até o momento (Manetti et al., 2009).

Devido as escassez de informações literárias a respeito de espécies do gênero Guzmania, o presente trabalho teve como objetivo realizar a caracterização anatômica, histoquímica e de classes de metabólitos secundários de Guzmania lingulata.

\section{MATERIAL E MÉTODOS}

Material botânico, anatomia e histoquímica

Para a realização do trabalho, 10 folhas de cinco espécimes de Guzmania lingulata (L.) Mez, possuidoras de limbo foliar bem expandido foram coletadas em abril de 2009 no viveiro de mudas do Centro Universitário Hermínio Ometto - UNIARARAS, município de Araras, SP. Um espécime fértil foi coletado e herborizado de acordo com as técnicas usuais (Mori et al., 1989) visando confirmação do táxon, sendo a exsicata obtida, tombada na coleção institucional (Voucher 135).

As folhas foram fixadas em FAA 50 e, posteriormente, transferidas para etanol $50 \%$ (Johansen, 1940). Para o estudo anatômico, secções

Rev. Bras. PI. Med., Campinas, v.16, n.1, p.127-134, 2014. 
transversais da porção mediana das lâminas foliares, obtidas à mão livre, foram submetidas ao processo de dupla coloração com safranina e azul de astra (Bukatsch, 1972; modificado apud Kraus \& Arduin, 1997) e montadas em gelatina glicerinada (Kaiser, 1880 apud Kraus \& Arduin, 1997).

Para os estudos histoquímicos, secções de material fresco foram submetidas à vanilina clorídrica (Mace \& Rowell, 1974), para evidenciação de compostos tânicos; ao hidróxido de potássio (Costa, 1982), para flavonóides; ao ácido sulfúrico concentrado e ao ácido acético glacial (Johansen, 1940), para saponinas e antocianinas, respectivamente. Os resultados foram documentados por meio de fotomicrografias com escala micrométrica fotografada nas mesmas condições.

\section{Extrato a frio e triagem de classes de metabólitos secundários}

Após a colheita, $500 \mathrm{~g}$ de folhas frescas foram selecionados aleatoriamente e limpas. Para desidratação, foram submetidas à estufa ventilada a $50^{\circ} \mathrm{C}$, posteriormente pulverizadas em moinho de facas, sendo o produto resultante $(425 \mathrm{~g})$, embebido em solução hidroalcoólica $70 \%$ por sete dias à temperatura ambiente. O material foi filtrado e o concentrado, submetido a evaporador rotatório sob pressão reduzida, a temperatura de até $50^{\circ} \mathrm{C}$, até um volume final de $100 \mathrm{~mL}$ o qual foi mantido em geladeira por $15 \mathrm{~h}$ (durante a noite) e então centrifugado. O resíduo foi desprezado, obtendose o Extrato Etanólico Bruto (EEB). A $50 \mathrm{~mL}$ de EEB foram adicionados $100 \mathrm{~mL}$ de água destilada. O extrato hidroalcoólico resultante $(150 \mathrm{~mL})$ foi desengordurado por partição com n-hexano em funil de separação até a fase hexânica apresentarse incolor. A fase hidroalcoólica resultante do processo anterior foi, então, particionada com diclorometano em funil de separação até que a fase diclorometânica se apresentasse incolor, resultando na fração diclorometano (FDCM). Em seguida procedeu-se o particionamento da fase hidroalcoólica remanescente com acetato de etila em funil de separação, até que a fase acetato de etila se apresentasse incolor, resultando na fração acetato de etila (FAE) (Kerber \& Silva, 1993).

Os grupos químicos testados foram: antocianinas, saponinas, flavonoides e taninos. Os testes para taninos foram realizados segundo os procedimentos descritos por Simões et al. (2007, cap. 9) na reação com a gelatina e, Schneider (1990) em reação com sais de ferro. Utilizaram-se também, vapores de iodo e soluções de $\mathrm{CeSO}_{4}$, para saponinas; reações de Shinoda, oxalo-bórica, com cloreto de alumínio, hidróxido de sódio a $20 \%$, cloreto férrico a $4,5 \%$ e com ácido sulfúrico concentrado, para flavonoides (Simões et al., 2007); para antocianos, foram utilizadas as técnicas de cores diferentes pela variação do $\mathrm{pH}$, como estabelecido por Moreira (1979).

\section{RESULTADOS E DISCUSSÃO}

\section{Caracterização anatômico foliar}

As folhas, em vista frontal, apresentaram escamas, que revestem ambas as faces (Fig. 1AB), estando dispostas ordenadamente em fileiras longitudinais na superfície adaxial das folhas (Fig. $1 \mathrm{~A})$ e distribuem-se de forma aleatória na superfície adaxial (Fig. 1B). Em vista frontal, evidencia-se apenas o escudo das escamas epidérmicas, que exibe uma só célula central (Fig. $1 \mathrm{Ca}$ ), de forma circular, que se encaixa formando um círculo de paredes finas. Essa célula central é circuncidada por uma camada de células de forma retangular, com paredes delgadas. Esta série de células é constituída de oitos células e são denominadas pericentrais (Fig. 1Cb). Externamente a essas células estão às células periféricas (Fig. $1 \mathrm{Cc}$ ), constituídas por cerca de 40 a 42 células. Estas se apresentam alongadas, dispostas radialmente e com paredes finas (Fig. 1C).

Em secção transversal, observou-se que as folhas apresentaram epiderme unisseriada revestida por cutícula relativamente delgada (Fig. 1D-F). As células epidérmicas mostraram paredes com grau de espessamento variável, apresentandose pouco espessadas, embora lignificadas. Em vista frontal, as células epidérmicas possuem contorno retangular (Fig. 2E). Segundo Krauss (1949), essa característica epidérmica aumenta a superfície de contato entre as células, conferindo uma maior resistência ao tecido epidérmico, durante as possíveis expansões e contrações foliares decorrentes da variação no turgor.

Nas folhas é comum a presença de uma hipoderme aquífera formada por células aclorofiladas e de paredes delgadas. Este tecido aparece na região adaxial das folhas (Fig. 1D). As primeiras camadas de células da hipoderme aquífera são constituídas por células arredondadas e as camadas subjacentes por células alongadas anticlinalmente (Fig. 1F; 2A).

$\mathrm{Na}$ maioria das folhas estudadas, o parênquima clorofiliano é constituído por células arredondadas (Fig. 1D). O mesofilo apresenta canais longitudinais de aeração situados entre os feixes vasculares que se comunicam com aerênquima constituído de células braciformes estreladas (Fig. $1 \mathrm{D} ; 1 \mathrm{~F} ; 2 \mathrm{C}$ ). Esses canais são contíguos às câmaras subestomáticas e atravessados por diafragmas formados por células braciformes (Fig. 2C). 


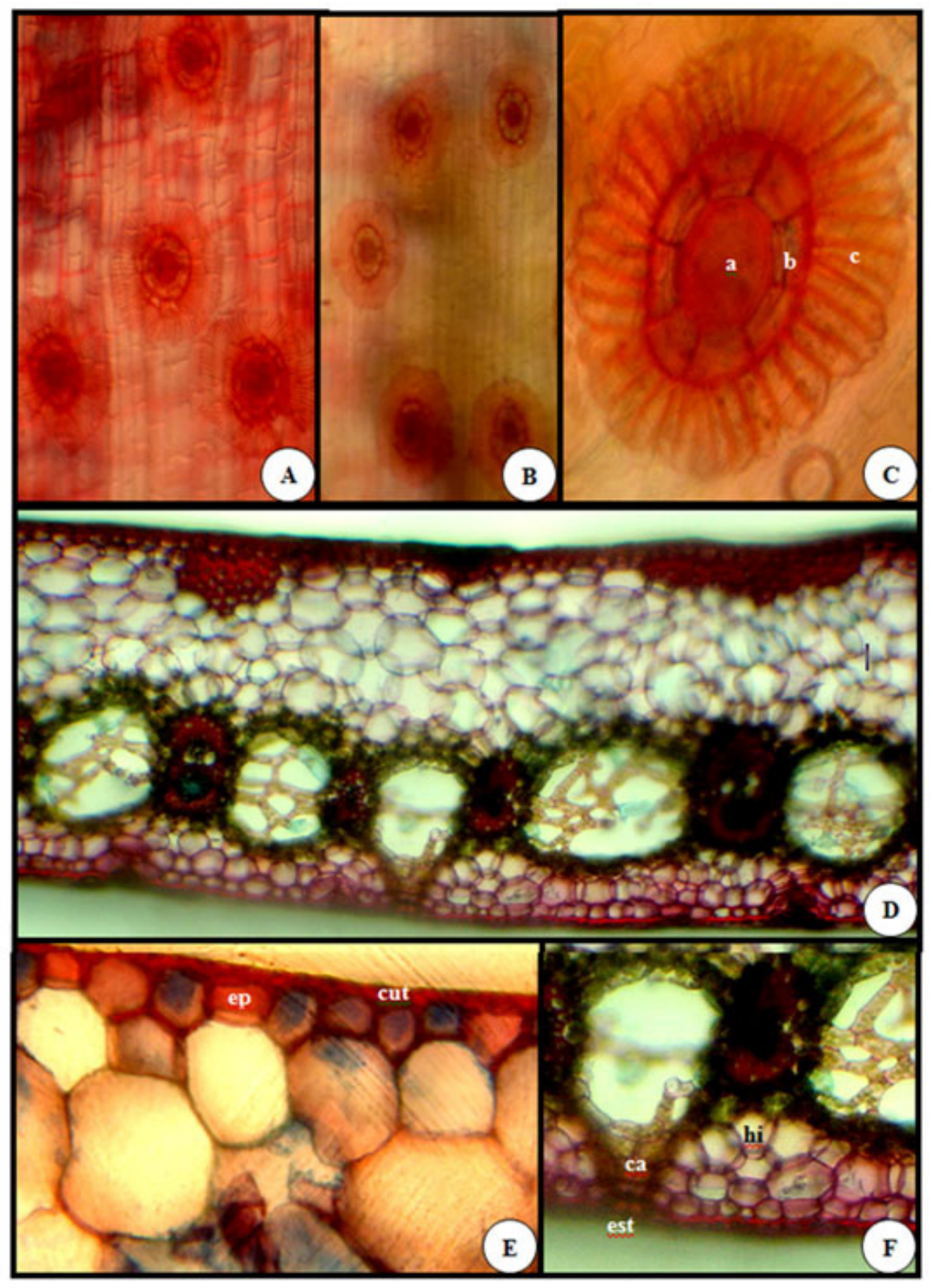

FIGURA 1. Secções frontais e transversais de folhas de Guzmania lingulata. Secção frontal da epiderme adaxial (A). Corte frontal da epiderme Adaxial (B). Escamas foliares (C). Secção transversal do limbo foliar (D). Secção transversal evidenciando epiderme adaxial $(E)$. Secção transversal evidenciando hidrênquima $(F)$. $a=$ célula central; $b$ = células pericentrais; $c$ = células periféricas; $c a=$ canal de aeração; cut = cutícula; ep = epiderme; est = estômato; hi = hidrênquima. Bars: Fig. A, B e D = $100 \mu \mathrm{m} ; \mathrm{C}$ e $E=10 \mu \mathrm{m} ; \mathrm{F}=50 \mu \mathrm{m}$.

Para a espécie, o mesofilo é homogêneo e compacto, constituído por células de contorno arredondado e com pequenos espaços intercelulares, assim como observado por Proença \& Sajo (2004), em vários gêneros de bromélias e por Voltolini \& Santos (2011) para Aechmea lindenii (E. Morren) Baker var. lindenii. Nas folhas observaram-se grupos de fibras não associados aos feixes vasculares. Esses grupos de fibras aparecem na face adaxial, próximo à epiderme e também são lignificados (Fig. 1D; 2A). Essas estruturas, não só aumentam a rigidez foliar oferecendo sustentação mecânica por ocasião de ventos fortes, como agem na proteção do mesofilo durante possíveis estresses hídricos e de temperatura, conforme descrito por Krauss (1949), Pyykkö (1966) e Brighina et al. (1984) para as folhas de Bromeliaceae e de outras famílias de angiospermas.

As folhas estudadas são anfiestomática e os estômatos se distribuem em fileiras longitudinais apresentando-se no nível da epiderme. Dentro de Bromeliaceae, a exposição das células-guarda é 


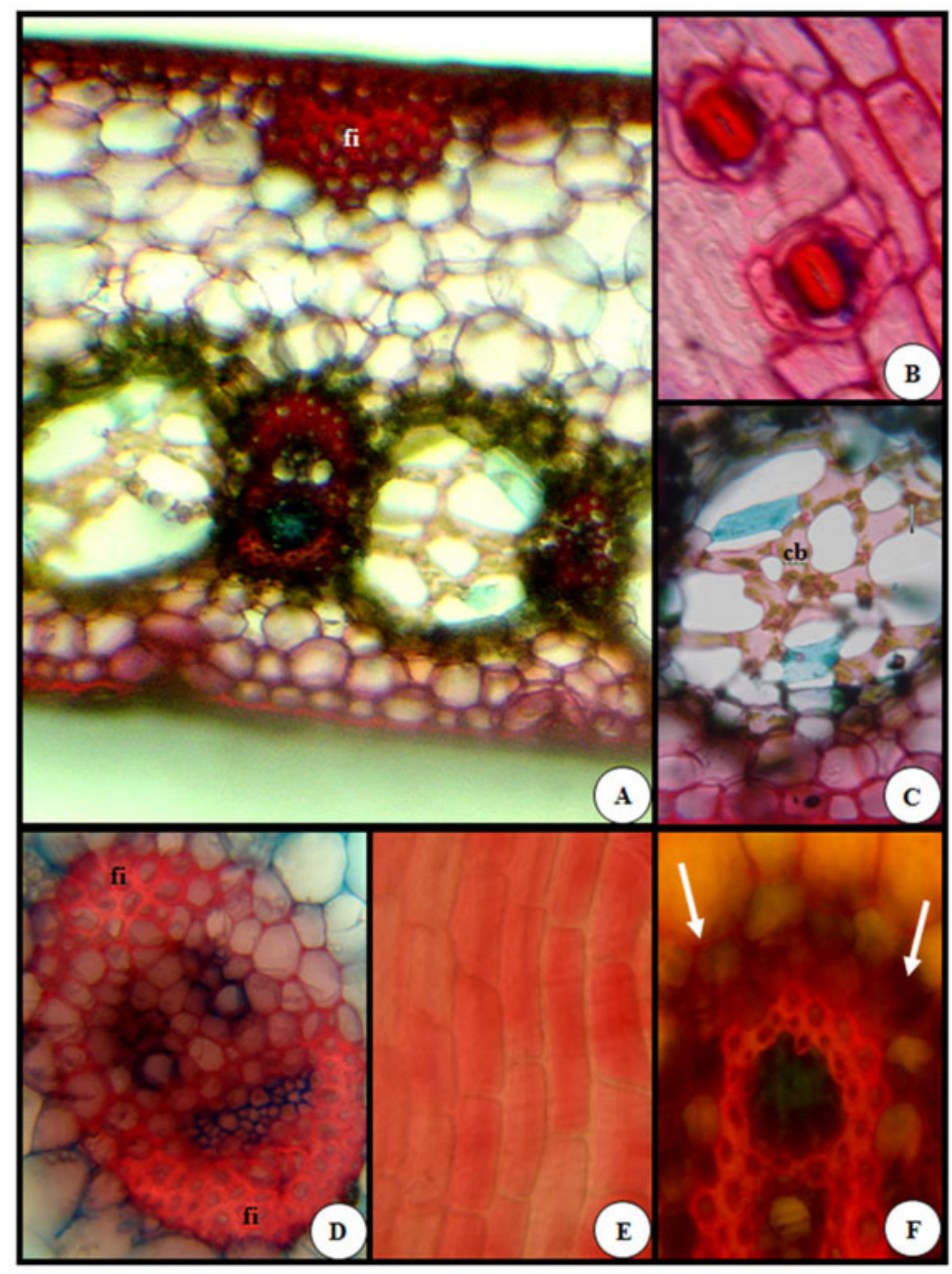

FIGURA 2. Secções transversais e frontais de folhas de Guzmania lingulata. Secção transversal evidenciando fibra esclerenquimática não associada a feixes condutores (A). Estômatos presentes na superfície abaxial (B). Aerênquima (C). Feixe vascular (D). Secção frontal invertida demonstrando células detentoras de antocianina (E). Presença de taninos (coloração verde-marrom) ao redor de feixe vascular $(F)$. $\mathrm{cb}=$ células braciformes; fi $=$ fibras esclerênquimáticas; setas $=$ taninos. Bars: Fig. $A=100 \mu \mathrm{m} ; \mathrm{C}$ e $\mathrm{E}=50 \mu \mathrm{m} ; \mathrm{B}, \mathrm{D}$ e $\mathrm{F}=10 \mu \mathrm{m}$.

um caráter variável entre as espécies, como pode ser verificado pelos resultados de Krauss (1949), Tomlinson (1969), Braga (1977); Sajo et al. (1998), Aoyama \& Sajo (2003), Arruda \& Costa (2003), Proença \& Sajo (2004), Scatena \& Segecin (2005), Sousa et al. (2005), Derwidueé \& Gonzalez (2010), Voltolini \& Santos (2011).

Na maioria das Bromelioideae, assim como em Guzmania lingulata, as folhas se caracterizam por apresentar superfície abaxial com regiões costais e intercostais bem demarcadas, com os estômatos alojados nas regiões intercostais (Fig. 2B). Essa localização particular dos estômatos provavelmente evita o excesso de transpiração, considerando-se que tais espécies ocorrem em áreas bem iluminadas (Martinelli, 1994).

Os feixes vasculares são colaterais e se dispõem numa única série ao longo das lâminas (Fig 1D). Geralmente, os feixes maiores se alternam com os menores e são circundados por 1-3 camadas de fibras pericíclicas, cujas paredes são espessadas e lignificadas. Os feixes menores são totalmente envolvidos por fibras completamente lignificadas (Fig. 2D). A camada de células parenquimáticas mais internas do mesofilo e que circunda as fibras pericíclicas representa a endoderme. 
Vale salientar que muitas das xeromorfias encontradas nas Bromeliaceae, embora possibilitem a exploração de ambientes extremos, representam adaptações ancestrais selecionadas durante a diversificação do grupo e não devem ser interpretadas apenas como caracteres relacionados a um ambiente particular onde elas vivem atualmente (Proença \& Sajo, 2007).

\section{Análise Histoquímica e de classes de metabólitos secundários}

Os resultados obtidos após a realização de testes histoquímicos e em relação às determinações de classes de metabólitos secundários mostraram presença de antocianinas e taninos, não sendo observada a presença de saponinas e flavonóides nos testes realizados (Tabela 1 ).

A ocorrência de antocianos na família Bromeliaceae permite destacar a importância química dos mesmos como possíveis agentes farmacológicos e, também, considerá-los como potenciais marcadores quimiotaxonômicos (Manetti et al., 2009). Em revisão realizada sobre as classes químicas da família, foram reportadas 20 antocianinas em 83 espécies de Bromeliaceae distribuídas pelas três subfamílias (Manetti et al., 2009). Contudo, as maiores contribuições em relação à identificação destes compostos foram as realizada por Saito \& Harborne (1983) em 34 espécies de diferentes subfamílias e por Scogin (1985) com a identificação de antocianinas em nove espécies dos gêneros Puya e Puyopsis.

As antocianinas possuem aproximadamente 300 variações moleculares e apresentam elevado número de propriedades farmacológicas, tais como: anti-inflamatórias, anti-úlcerais, anticonvulsantes, antioxidantes, cardioprotetoras, vasoprotetoras, vasodilatadoras, redutoras da permeabilidade e fragilidade dos vasos, no controle de infecções oftalmológicas, redução no nível de colesterol e triglicérides, protetoras contra a degradação de células, além de proteger contra a indução de danos causados no DNA por tert-butil-hidroperóxido, protetoras contra o vírus Influenza (gripe) e quando em combinação com o ácido elágico, desenvolve uma potente ação preventiva contra certos tipos de cânceres (Guedes, 2004).
Antocianinas são pigmentos pertencentes ao grupo dos flavonóides que beneficiam a planta na proteção contra raios ultravioleta e consequentemente, diminuem a temperatura foliar (Taiz \& Zeiger, 2004; Raven et al., 2007). Tais pigmentos também são responsáveis pela coloração dos vegetais (que varia do laranja ao azul, conforme o $\mathrm{pH}$ ), sendo encontrados também em flores, frutos e raízes. Devido a esta característica, seu vínculo com a planta estende-se também a agir como atrativo de insetos e pássaros, objetivando a polinização e dispersão de sementes (Zuanazzi, 1999; Taiz \& Zeiger, 2004).

A coloração rosa aparente no teste histoquímico (Figura 2E), se deve a antocianina em pH abaixo de 3,0 e copigmentos, que podem ser flavonóides não antociânicos, alcalóides, aminoácidos e nucleosídeos (Stringheta \& Bobbio, 2000).

Taninos, pertencentes ao grupo dos polifenóis, quando ocorrem em grande quantidade, geralmente se localizam em órgãos específicos da planta como as folhas, os frutos ou caules (Roberts et al., 1997). Neste trabalho, tal metabólito foi identificado próximo aos feixes condutores foliares (Figura 2F, setas). Esta localização está diretamente relacionada com a proteção da planta, uma vez que impede o desenvolvimento de doenças patogênicas no interior da folha devido à atividade anti-radicalar do metabólito (Taiz \& Zeiger, 2004).

Assim como neste trabalho, a presença de taninos também foi reportada para a espécie nacional, Bromelia antiacantha Bertol., a qual apresentou devido à seus compostos fenólicos, atividade antimicrobiana, citotóxica, moluscicida e antioxidante (Manetti et al., 2010). Tais resultados corroboram com a constatação de Simões et al. (2007), de que testes realizados com extratos ricos em taninos ou com taninos puros têm obtido resultados positivos para diversas atividades biológicas, podendo-se citar a atividade bactericida e fungicida, antiviral, inibição da peroxidação de lipídeos e sequestrador de radicais livres. Outra característica bastante ressaltada por diversos autores é o sabor adstringente dos taninos, repulsando insetos, répteis, pássaros e mamíferos.

Haslam (1998) relata que as atividades

TABELA 1. Identificação de metabólitos secundários nos testes histoquímicos e de classes de metabólitos secundários realizados para Guzmania lingulata.

\begin{tabular}{ccccc}
\hline & Antocianinas & $\begin{array}{c}\text { Flavonóides } \\
\text { Teste Realizado }\end{array}$ & Saponinas & Taninos \\
\hline Fitoquímico & & - & - & + \\
Histoquímico & + & - & - & + \\
\hline
\end{tabular}

(+) para teste positivo; (-) para teste negativo.

Rev. Bras. PI. Med., Campinas, v.16, n.1, p.127-134, 2014. 
farmacológicas destes metabólitos no tratamento de doenças estão diretamente relacionadas, pelo menos em parte, a três características gerais que são comuns aos taninos condensados e aos taninos hidrolisáveis que incluem a atividade antioxidante e sequestradora de radicais livres, a complexação com íons metálicos (ferro, manganês, vanádio, cobre, alumínio, cálcio, entre outros) além da habilidade de se complexar com outras moléculas, incluindo macromoléculas (como proteínas e polissacarídeos).

Além de apresentarem atividades farmacológicas relatadas, segundo Roberts et al. (1997), há indícios epidemiológicos e experimentais que levam a crer que os taninos possuem perigoso potencial carcinogênico. Porém, estudos recentemente realizados com taninos condensados evidenciaram a ação antioxidante muito eficaz no controle de radicais livres.

\section{CONCLUSÃO}

- Os resultados demonstraram que foi possível realizar a caracterização anatômico foliar baseada na qualidade das imagens obtidas, sendo que os caracteres encontrados representam adaptações ancestrais selecionadas durante a derivação da família;

- Detectou-se a presença de antocianinas e taninos nas folhas da espécie Guzmania lingulata (L) Mez. pelos testes propostos;

- Esses resultados estimulam a realização de estudos mais aprofundados para identificar e quantificar os compostos dessas e de outras classes de metabólitos.

\section{REFERÊNCIA}

AGRA, M.F.; FREITAS, P.F.; BARBOSA-FILHO, J.M. Synopsis of the plants known as medicinal and poisonous in Northeast of Brazil. Revista Brasileira de Farmacognosia, v. 17, p. 114-140, 2007.

ALONSO-PAZ, E.; CERDEIRAS, MP.; FERNANDEZ, J.; FERREIRA, F.; MOYNA, P.; VAZQUEZ, A.; VERO, S.; ZUNINO, L. Screening of Uruguayan medicinal plants for antimicrobial activity. Journal of Ethnopharmacology, v. 45, p. 67-70, 1995.

AOYAMA, E.M.; SAJO, M.G. Estrutura foliar de Aechmea Ruiz \& Pav. subgênero Lamprococcus (Beer) Baker e espécies relacionadas. Revista Brasileira de Botânica, n 26, p. 461-473, 2003.

ARRUDA, R.C.O.; COSTA, A.F. Foliar anatomy of five Vriesea sect. Xiphion (Bromeliaceae) species. Selbyana, v. 24, p.180-189, 2003.

BENNETT, B.C. Ethnobotany of Bromeliaceae. In: BENZING, D.H. Bromeliaceae: Profile of an adaptive radiation. New York: Cambridge University Press, 2000. p. 245-328.

BENZING, D.H. Bromeliaceae: Profile of an adaptive radiation. New York: Cambridge University Press, 2000. 690p.

BRAGA, M.M.N. Anatomia foliar de Bromeliaceae da Campina. Acta Amazonica, v.7, p. 1-74, 1977.

BRIGHIGNA, L.; FIORDI, A.C.; PALANDRI, M.R. Strutural characteristics of mesophyll in some Tillandsia species. Phytomorphology, v.34, p.191-200, 1984.

CORREAA, M.P. Dicionário das Plantas Úteis do Brasil e das Exóticas Cultivadas. Vol. 2. Rio de Janeiro: IBDF, 1984. 707p.

COSTA, A.F. Farmacognosia. Lisboa: Fundação Calouste Gulbenkian, 1982. 82p.

CRUZ, G.L. Dicionário de Plantas Úteis do Brasil. 5. ed. Rio de Janeiro : Bertrand Brasil, 1995. 600p.

DERWIDUEE, F.S.; GONZALEZ, A.M. Anatomía foliar en Bromeliaceae del Nordeste Argentino y Paraguay. Bonplandia, v.19, p. 153-173, 2010.

DUKE, J.A.; BOGENSCHUTZ-GODWIN, M.J.; DUCELLIER, J.; DUKE, P.A.K. Handbook of medicinal herbs. 2. ed. Boca Raton: CRC Press, 2002. 936p.

FRANCO, E.A.P.; BARROS, R.F.M. Uso e Diversidade de Plantas Medicinais no Quilombo Olho D'água dos Pires, Esperantina, Piauí. Revista Brasileira de Plantas Medicinais, v. 8, p. 78-88, 2006.

GUEDES, M.C. Antocianinas: pigmento natural ou remédio? Revista Científica do IMAPES, v.2, p. 7174, 2004.

HASLAM, E. Pratical polyphenols - from structure to molecular recognition and physiological action. Cambrige: Cambrige University, 1998. 67p.

JOHANSEN, D.A. Plant microtechnique. New York: MacGraw-Hill Book Company, 1940. 46p.

KERBER, V.A.; SILVA, G.A.A.B. Flavonoides de Acacia longifólia (Andr) Willd-Leguminosae-Mimosoidae. Revista Brasileira de Farmacognosia, v. 74, p. 1618, 1993.

KRAUSS, B.H. Anatomy of the vegetative organs of the Pineapple, Ananas comosus (L.) Merr. II - The leaf. Botanical Gazette, v. 110, p. 333-404, 1949.

KRAUS, J.E.; ARDUIN, M. Manual básico de métodos em morfologia vegetal. Seropédica: UFRRJ, 1997. $198 p$.

LUTHER. R. An alphabetical list of Bromeliad binomials. Sarasota: The Bromeliad Society International, 2004. $62 p$.

MACE, M.E.; HOWELL, C.R. Histochemistry and identification of condensed tannin precursor in roots of cotton seedlings. Canadian Journal of Botany, v. 52, p. 2423-2426, 1974.

MANETTI, L.M.; DELAPORTE, R.H.; LAVERDE JR., A. Metabólitos secundários da família bromeliaceae. Química Nova, v. 32, n. 7, 2009.

MANETTI, L.M.; TURRA, A.F.; TAKEMURA, O.S.; SVIDZINSKI, T.I.E.; LAVERDE JUNIOR, A. Avaliação das atividades antimicrobiana, citotóxica, moluscicida e antioxidante de Bromelia antiacantha Bertol. (Bromeliaceae). Revista Brasileira de Plantas Medicinais, v.12, p. 406-413, 2010.

MARTINELLI, G. Reproductive Biology of Bromeliaceae in the Atlantic Rain Forest of Southeastern Brazil. 1994. 166p. Tese (Doutorado). University of St. Andrews, St. Andrews.

MOREIRA, E.A. Contribuição ao estudo fitoquímico de 
Lobelia hassleri A. Zahlb e Lobelia stellfeladii R. Braga. Campanulaceae. Tribuna Farmacêutica, v. 5, p. 1339, 1979.

MORI, S.A.; SILVA, L.A.M.; LISBOA, G.; CORADIN, L. Manual de manejo do herbário fanerogâmico. Ilhéus: Centro de Pesquisa do Cacau, 1989. 104p.

PROENÇA, S.L.; SAJO, M.G. Estrutura foliar de espécies de Aechmea Ruiz \& Pav. (Bromeliaceae) do Estado de São Paulo. Acta Botanica Brasilica, v.18, p. 319-331, 2004.

PROENÇA, S.L.; SAJO, M.G. Anatomia foliar de bromélias ocorrentes em áreas de cerrado do Estado de São Paulo. Acta Botanica Brasilica, v. 21, p. 657-673, 2007.

PYYKKÖ, M. The leaf anatomy of East Patagonian xeromorphic plants. Annales Botanici Fennici, v. 3, p. 453-622, 1966.

RAVEN, P.H.; EVERT, R.F.; EICHHORN, S.E. Biologia Vegetal. 7ed. Rio de Janeiro: Guanabara Koogan, 2007. 813 p.

REITZ, R. Bromeliáceas e a Malária-Bromélia Endêmica. In: REITZ, R. Flora llustrada Catarinense, parte I, fascículo Bromélias. Itajaí: Herbário Barbosa Rodrigues, 1983. p. 1-808.

RIOS. R.; KHAN, B. List of etnobothanical uses of Bromeliaceae. Journal of the Bromeliad Society, v. 48, p. 75-87, 1998.

ROBERTS, J.E.; SPEEDIE, M.K.; TYLER, V.E. Farmacognosia e Farmacobiotecnologia. São Paulo: Premier. 1997. 93p.

RODRIGUES, V.E.G.; CARVALHO, D.A. Levantamento etnobotânico de plantas medicinais no domínio dos cerrados na região do Alto Rio Grande - Minas Gerais. Revista Brasileira de Plantas Medicinais, v.9, n.2, p.17-35, 2007.

SAITO, N. \& HARBORNE, J. B. A cyanidin glycoside giving scarlet coloration in plants of the Bromeliaceae. Phytochemistry, v. 22, p. 1735-1740, 1983.

SAJO, M.G.; MACHADO, S.R.; CARMELLO-GUERREIRO, S.M. Aspectos estruturais de folhas de bromélias e suas implicações no agrupamento de espécies. In: PEREIRA, M.V. Bromélias da Mata Atlântica: Canistropsis. Rio de Janeiro: Salamandra Consultoria, 1998. p. 102-111.

SCATENA, V.L.; SEGECIN, S. Anatomia foliar de Tillandsia L. (Bromeliaceae) dos Campos Gerais, Paraná, Brasil. Revista Brasileira de Botânica, v. 28, p. 635-649, 2005.

SCHNEIDER, G. Arzneidrogen-ein kompendium für pharmazeuten, biologen und chemiker. Mannheim:
Wissenschaftsverlag, 1990. 81p.

SCOGIN, R. Floral anthocyanins in the genus Puya. Biochemical Systematics and Ecology, v. 13, p. 387-389, 1985.

SIMÕES C.M.O; SCHEMKEL E.P; GOSMANN G; MELLO J.C.P; MENTZ L.A.; PETROVICK P.R. Farmacognosia: da Planta ao Medicamento. 6. ed. Florianópolis: UFSC, 2007. 821p.

SOUSA, G.M.; ESTELITA, M.E.M.; WANDERLEY, M.G.L. Anatomia foliar de espécies brasileiras de Aechmea subg. Chevaliera (Gaudich. ex Beer) Baker, Bromelioideae - Bromeliaceae. Revista Brasileira de Botânica, v. 28, p. 603-613, 2005.

STRINGHETA, P.C.; BOBBIO, P.A. Copigmentação de Antocianinas: uso de corantes naturais em alimentos processados. Biotecnologia Ciência e Desenvolvimento, v. 14, p. 34-37, 2000.

TAIZ, L.; ZEIGER, E. Fisiologia Vegetal. 3. ed. Porto Alegre: Artmed, 2004. 203p.

TOMLINSON, P.B. Comelinales - Zingiberales. In: C.R. METCALF. Anatomy of the monocotyledons: III. Oxford: Claredon, 1969. p. 193-294.

VIEIRA-DE-ABREU, A.; AMENDOEIRA, F.C.; GOMES, G.C.; ZANON, C.; CHEIDER, L.C.; FIGUEIREDO, M.R.; KAPLAN, M.A.C.; FRUTUOSO, V.S.; CASTRO-FARIANETO, H.C.; WELLER, P.F.; BANDEIRA-MELO, C.; BOZZA, P.T. Anti-allergic properties of the bromiliaceae Nidularium procerum:Inhibition of eosinophil actibation and influx. International Immunopharmacology, v. 5, p. 1966-1974, 2005.

WAGNER, H.M.; BLADT, S.; ZGAINKI, E.M. Plant drug analysis. Berlim: Springer, 1984. 303p.

WHITERUP, K.M.; MCLAUGHLIN, J.L.; JUDD, R.L.; ZIEGLER, M.H.; MEDON, P.J.; KELLER, W.J. Identification of 3-Hydroxy-3-methylglutaric Acid (HMG) as a Hypoglycemic Principle of Spanish Moss (Tillandsia usneoides). Journal of Natural Products, v. 58, p. 1285-1290, 1995.

VOLTOLINO, C. H.; SANTOS, M. Variações na morfoanatomia foliar de Aechmea lindenii (E. Morren) Baker var. lindenii (Bromeliaceae) sob distintas condições ambientais. Acta Botanica Brasilica, v. 25, p. 2-10, 2011

ZUANAZZI, J.A.S. Flavonóides. In: SIMÕES, C.M.O.; SCHENKEL, E.P.; GOSMANN, G.; MELLO, J.C.P.; MENTZ, L.A.; PETROVICK, P.R. Farmacognosia: da planta ao medicamento. 6. ed. Florianópolis: UFSC, 2007. p. 577-614. 